\title{
Kodiranje informacije o vrstnem redu v delovnem spominu: pregled vedenjskih raziskav in kognitivnih mehanizmov
}

\author{
Barbara Dolenc ${ }^{*}$ in Grega Repovš ${ }^{2}$ \\ ${ }^{1}$ Družbenomedicinski inštitut, Znanstvenoraziskovalni center Slovenske akademije znanosti in umetnosti \\ ${ }^{2}$ Oddelek za psihologijo, Filozofska fakulteta, Univerza v Ljubljani
}

\begin{abstract}
Povzetek: Za kognitivne naloge višjega reda so izredno pomembni izvršilni procesi, med katere spada tudi kodiranje časovnega vrstnega reda informacij. Pomembno vprašanje je, kako se vrstni red kodira ter kateri kognitivni in živčni procesi tvorijo njegovo podlago. Namen pričujočega članka je povzeti izsledke raziskav, ki preverjajo, ali spomina za vrstni red in prepoznavo dražljajev temeljita na ločenih procesih, ter pregledati nekaj osnovnih kognitivnih mehanizmov, ki razlagajo kodiranje vrstnega reda informacij v delovnem spominu. Številne študije kažejo, da so informacije o lastnostih oziroma identiteti dražljajev ter njihovemu vrstnem redu v spominu predstavljene in procesirane ločeno, tako pri prepoznavi, kot pri priklicu. Ločeno procesiranje obeh vrst informacij podpirajo ne le vedenjske, temveč tudi številne slikovne študije. Kako se kodirajo informacije o vrstnem redu, skuša pojasniti več teoretskih modelov. V tem članku bomo pregledali štiri skupine modelov, ki temeljijo na mehanizmu meddražljajskih povezav oziroma verižnega kodiranja, mehanizmu neposrednega ali direktnega kodiranja, mehanizmu hierarhičnega kodiranja ter mehanizmu velikostnega kodiranja. Modeli se razlikujejo tako glede vedenjskih napovedi kot tudi glede predpostavljenih živčnih mehanizmov, na katerih temeljijo. Vsak izmed predlaganih mehanizmov pri tem uspešno pojasnjuje nekatere vidike procesiranja vrstnega reda, nobenemu pa ne uspe pojasniti vseh obstoječih spoznanj in rezultatov študij vrstnega reda. Spomin za zaporedje predstavlja kompleksen proces, zato je verjetno, da je vrstni red kodiran in procesiran s pomočjo več kot le enega mehanizma. Obstoječa spoznanja in modeli puščajo obilico odprtih vprašanj ter nakazujejo možnost obstoja več različnih vrst spomina za vrstni red informacij.
\end{abstract}

Ključne besede: delovni spomin, kodiranje vrstnega reda, kognitivni mehanizmi

\section{Order information coding in working memory: Review of behavioural studies and cognitive mechanisms}

\author{
Barbara Dolenc ${ }^{1}$ and Grega Repovš ${ }^{2}$ \\ ${ }^{1}$ Sociomedical Institute, Research Centre of the Slovenian Academy of Sciences and Arts, Slovenia \\ ${ }^{2}$ Department of Psychology, Faculty of Arts, University of Ljubljana, Slovenia
}

\begin{abstract}
Executive processes, such as coding for sequential order, are of extreme importance for higher-order cognitive tasks. One of the significant questions is, how order information is coded in working memory and what cognitive mechanisms and processes mediate it. The aim of this review paper is to summarize results of studies that explore whether order and item memory are two separable processes. Furthermore, we reviewed evidence for each of the proposed cognitive mechanism that might mediate order processing. Previous behavioural and neuroimaging data suggest different representation and processing of item and order information in working memory. Both information are maintained and recalled separately and this separation seems to hold for recognition as well as for recall. To explain the result of studies of order coding, numerous cognitive mechanisms were proposed. We focused on four different mechanisms by which order information might be coded and retrieved, namely inter-item associations, direct coding, hierarchical coding and magnitude coding. Each of the mechanisms can explain some of the aspect of order information coding, however none of them is able to explain all of the empirical findings. Due to its complex nature it is not surprising that a single mechanism has difficulties accounting for all the behavioral data and order memory may be more accurately characterized as the result of a set of mechanisms rather than a single one. Moreover, the findings beget a question of whether different types of memory for order information might exist.
\end{abstract}

Key words: working memory, serial order coding, cognitive mechanisms

\footnotetext{
"Naslov/Address: Barbara Dolenc, Družbenomedicinski inštitut, Znanstvenoraziskovalni center Slovenske akademije znanosti in umetnosti, Novi trg 2, 1000 Ljubljana, e-pošta: barbara.dolenc@zrc-sazu.si
}

Članek je licenciran pod pogoji Creative Commons Attribution 4.0 International licence. (CC-BY licenca).

The article is licensed under a Creative Commons Attribution 4.0 International License (CC-BY license). 
V literaturi lahko zasledimo več opredelitev delovnega spomina - nekateri ga opisujejo kot kognitivni sistem za začasno hrambo in manipulacijo informacij, ki so trenutno v spominu (Baddeley, 1986; 2002; 2003; 2007), drugi kot tip spomina, ki je aktiven in relevanten samo za kratko časovno obdobje (Goldman-Rakic, 1995), in tretji kot proces, s pomočjo katerega je dražljaj, ki ga držimo v spominu, ves čas na dosegu, da vodi vedenje v odsotnosti zunanjihdražljajev(Goldman-Rakic, 1996). Kljubnekoliko različnim opredelitvam pa se avtorji strinjajo, da delovni spomin obsega niz temeljnih procesov, ki omogočajo in so sestavni del številnih kognitivnih sposobnosti (Baddeley, 1986; 2007; Owen, McMillan, Laird in Bullmore, 2005). Delovni spomin je nujen za višje kognitivne procese, kot so branje (Carretti, Borella, Cornoldi in De Beni, 2009; Daneman in Merikle, 1996), sklepanje (Baddeley, 1986; Salthouse, 1993), jezikovno razumevanje besedišča (Just in Carpenter, 1992) ter reševanje problemov (Kyllonen in Christal, 1990; Zheng, Swanson in Marcoulides, 2011).

Čeprav so nekateri sprva menili, da je delovni spomin enoten mehanizem (Cantor in Engle, 1993; Cowan, 1993; Just in Carpenter, 1992), je danes širše sprejeto, da obstaja več ločenih podsistemov delovnega spomina, ki obsegajo shrambe in spremljajoče procese za vzdrževanje verbalnih in vidno-prostorskih informacij (Baddeley, 2002; 2003; 2007; Jonides, Lacey in Nee, 2005). Ta pogled podpirajo številne vedenjske in slikovne študije (na primer: Awh idr., 1996; D’Esposito, Postle, Ballard in Lease, 1999; Henson, Burgess in Frith, 2000; Johnson, Raye, Mitchell, Greene in Anderson, 2003; Smith in Jonides, 1999; Smith, Jonides in Koeppe, 1996). Najbolj znan in splošno sprejet je multikomponentni model delovnega spomina (Baddeley, 1986; 2003), ki loči štiri temeljne podsisteme: verbalno shrambo z mehanizmi ponavljanja, ki služijo aktivnemu vzdrževanju verbalnih informacij, vidnoprostorsko skicirko za vzdrževanje neverbalnih informacij, epizodični medpomnilnik, ki omogoča hranjenje integriranih multimodalnih reprezentacij, ter centralnega izvršitelja, ki obsega procese za manipulacijo informacij in nadzor ostalih podsistemov.

Za kognitivne naloge višjega reda so izredno pomembni prav izvršilni procesi. Kompleksnejše naloge namreč aktivirajo izvršilne procese za nadzor in usklajevanje posameznih komponent delovnega spomina (Baddeley, 2003; 2007; Marshuetz, Smith, Jonides, DeGutis in Chenevert, 2000). Med izvršilne procese spadajo tudi sposobnost inhibicije (Jonides, Smith, Marshuetz, Koeppe in Reuter-Lorenz, 1998; Kane in Engle, 2002), menjavanja med različnimi nalogami (D’Esposito idr., 1995) ter kodiranja časovnega vrstnega reda oziroma zaporedij informacij v spominu (Cabeza idr., 1997; Cabeza, Nichole, Houlse, Mangels in Nyberg, 2000; D’Esposito idr., 1999; Smith in Jonides, 1999). Znotraj sistema delovnega spomina imamo torej mehanizme, ki omogočajo kodiranje informacij o vrstnem redu. Pomembno vprašanje je, na kakšen način so informacije o vrstnem redu zabeležene ter kateri kognitivni in živčni mehanizmi to beleženje omogočajo.

\section{Delovni spomin za vrstni red}

Sposobnost beleženja in vzdrževanja informacij o zaporedju dogodkov v delovnem spominu je pomembna iz mnogo vidikov človeške kognicije. Pogosto vedeti »kaj« enostavno ni dovolj, ampak si moramo zapomniti tudi »kdaj« in »v kakšnem vrstnem redu« so se določene informacije pojavile. Ko prejmemo navodila o tem, kako $\mathrm{v}$ neznanem kraju priti od točke A do točke B, ni dovolj, da si zapomnimo le koliko levih in desnih ovinkov nas loči od cilja, temveč si moramo zapomniti tudi njihovo točno zaporedje. Procesiranje vrstnega reda pa je še posebno pomembno pri kognitivnih procesih višjega reda, kot je razumevanje besedišča ter produkcija govora (Acheson in MacDonald, 2009; Burgess in Hitch, 1999; Dell, Burger in Svec, 1997; Gathercole in Baddeley, 1990; Gupta in MacWhinney, 1997; Leclercq in Majerus, 2010).

Večina spoznanj o delovnem spominu za vrstni red temelji na dveh vrstah raziskav. V raziskavah zaporednega priklica (angl. serial recall, Sternberg, 1966) je naloga udeleženca zapomniti si niz prikazanih dražljajev, nato pa jih priklicati v ustreznem vrstnem redu. Študije zaporednega priklica se osredotočajo predvsem na vrste napak, kijih naredimo pri takšnem priklicu. Druga skupina raziskav pa se osredotoča na razliko med prepoznavanjem dražljajev in njihovega vrstnega reda (Marshuetz, 2005). V nalogah prepoznavanja dražljajev udeležencem naročimo, naj si zapomnijo niz dražljajev, nato pa jim prikažemo ciljni dražljaj za katerega mora udeleženec povedati, ali je bil del izvirnega niza. $\mathrm{V}$ primeru naloge vrstnega reda pa sta ciljna dražljaja dva, udeleženec pa mora podati sodbo o pravilnosti njunega položaja glede na izvirni niz (Marshuetz, 2005; McElree in Dosher, 1993; Sternberg, 1967). S primerjanjem odgovorov pri obeh vrstah nalog lahko lastnosti prepoznavanja dražljajev primerjamo s pomnjenjem njihovega zaporedja (Marshuetz, 2005).

V nadaljevanju se bomo najprej posvetili raziskavam, ki preverjajo hipotezo, da sta spomin za vrstni red in prepoznavo dražljajev dva ločena procesa. Zatem pa bomo pregledali kognitivne mehanizme, s pomočjo katerih lahko pojasnimo lastnosti kodiranja in procesiranja vrstnega reda informacij v delovnem spominu.

\section{Prepoznavanje identitete in vrstnega reda dražljajev - en sam ali dva različna procesa?}

Vedenjski rezultati, ki podpirajo ločeno procesiranje informacij o lastnostih dražljajev in njihovem vrstnem redu, so nastali na podlagi nalog zaporednega priklica (Sternberg, 1966). V tej nalogi se pogosto pojavijo napake, ko si udeleženec pravilno zapomni identiteto dražljajev vendar v napačnem vrstnem redu. Tovrstno zamenjavo dražljajev oziroma pravilen priklic dražljajev $\mathrm{v}$ nepravilnem vrstnem redu, imenujemo napaka transpozicije (Marshuetz, 2005). Vsi raziskovalci niso mnenja, da napaka transpozicije nujno kaže na izgubo 
informacije o vrstnem redu. Conrad (1965) je mnenja, da mnogo napak v priklicu vrstnega reda dražljajev odraža napako v pomnenju njihove identitete. Specifične dražljaje v nizu, ki si ga je potrebno zapomniti, posameznik zameša zato, ker so si akustično podobni, akustična zmeda pa daje vtis, da gre za napako v priklicu vrstnega reda. Tej predpostavki je sledil niz raziskav o vzdrževanju akustično zamenljivih in nezamenljivih dražljajev, katerih rezultate povzemamo $\mathrm{v}$ nadaljevanju.

Bjork in Healy (1974) sta bila za razliko od Conrada (1965) mnenja, da so informacije o identiteti in lastnostih dražljajev na eni in vrstnem redu na drugi strani v spominu vzdrževane ločeno. Izvedla sta eksperiment, v katerem so morali udeleženci priklicati štiri soglasnike, kjer je spominski niz vseboval nič ali dva akustično zamenljiva dražljaja. Avtorja sta pokazala, da se akustična zamenjava ni pojavila večkrat kot bi to pričakovali po naključju. $Z$ manipulacijo dolžine vzdrževanja infromacij sta pokazala tudi, da se informacija o vrstnem redu dražljajev $\mathrm{z}$ daljšanjem vzdrževanja izgublja hitreje kot informacija o njihovi identiteti. Pri najkrajšem vzdrževanju so udeleženci le redko izgubili informacijo o lastnostih dražljajev, v spominski niz niso vsiljevali dražljajev, ki izvorno niso bili prikazani, in so tako naredili le malo napak. V nasprotju s tem pa so se pri daljših vzdrževanjih večkrat pojavljale napake transpozicije - udeleženci so priklicali pravilne dražljaje, a v napačnem vrstnem redu. Avtorja sta zaključila, da akustične zamenjave niso edina razlaga napak v spominu za vrstni red in da so informacije o zaporedju lahko izgubljene ločeno od informacij o identiteti dražljajev (Bjork in Healy, 1974).

Sternberg (1967) je primerjal rezultate naloge iskanja naslednika $\mathrm{z}$ nalogo prepoznavanja dražljajev. $\mathrm{V}$ obeh nalogah je udeležencem prikazal niz treh do sedmih številčnih dražljajev. V primeru prepoznavanja dražljajev so morali udeleženci zgolj podati sodbo o tem, ali je prikazan ciljni dražljaj bil del začetnega zaporedja ali ne. $\mathrm{V}$ nalogi iskanja naslednika pa so morali glasno povedati, kateri dražljaj je v začetnem zaporedju sledil prikazanemu dražljaju. Sternberg je na podlagi odnosa reakcijskih časov v odvisnosti od števila dražljajev, ki si jih je bilo potrebno zapomniti, ugotovil, da z velikostjo niza reakcijski časi pri nalogi iskanja naslednika naraščajo $7 \mathrm{x}$ hitreje kot pri nalogi prepoznavanja dražljajev. Zaključil je, da so za spomin za prepoznavanje dražljajev in vrstni red odgovorni kvalitativno drugačni mehanizmi priklica, pri čemer je pri prepoznavanju dražljajev vpleteno hitro skeniranje dražljajev, pri vrstnem redu pa počasno iskanje tarče (Marshuetz, 2005).

Procesiranje lastnosti dražljajev in njihovega zaporedja naj bi prav tako potekalo $\mathrm{z}$ različno hitrostjo. McElree in Dosher (1993) sta pregledala časovni potek oziroma razlikovalno stopnjo zbiranja informacij o lastnostih dražljajev in njihovemu vrstnemu redu $\mathrm{v}$ spominu. Udeležencem sta prikazala zaporedje šestih soglasnikov, ciljni dražljaj pa je vedno vseboval dve črki. V pogoju vrstnega reda sta bili obe črki iz začetnega seta, udeleženci pa so morali povedati, katera izmed prikazanih črk se je v zaporedju pojavila prej. V pogoju identitete oziroma prepoznavanja dražljajev pa je bil eden izmed ciljnih dražljajev prisoten v izvirnem nizu, drugi pa ne, udeleženec pa je moral prepoznati, kateri izmed dražljajev je bil prisoten v izvirnem nizu. Rezultati so pri presoji zaporedja pokazali močan učinek zadnjega dražljaja. Udeleženci so podajali bolj pravilne sodbe o vrstnem redu takrat, kadar je bil eden izmed ciljnih dražljajev prikazan na zadnjem mestu $\mathrm{v}$ izvornem nizu, kar po mnenju avtorjev kaže na zaporedni priklic informacije o vrstnem redu. V pogoju identitete učinek položaja ni bil prisoten, na podlagi česar avtorja sklepata, da je informacija o dražljaju priklicana s pomočjo vzporednih mehanizmov, ki imajo neposreden dostop do dražljaja. Na podlagi opisanih razlik avtorja zaključujeta, da se informacije o lastnostih dražljajev in njihovem vrstnem redu procesirajo z drugačnimi mehanizmi. Sorodne raziskave (Henderson in Matthews, 1970) poleg tega kažejo, da hiter prikaz dražljajev veliko bolj vpliva na kodiranje vrstnega reda kot pa na kodiranje lastnosti dražljajev, kar prav tako kaže, da se informacije o vrstnem redu v spominu kodirajo počasneje kot pa informacije o identiteti dražljajev. Opisani izsledki potrjujejo predpostavko o ločenem procesiranju informacije o identiteti in vrstnem redu $\mathrm{v}$ delovnem spominu, pri čemer je procesiranje vrstnega reda počasnejše in zahtevnejše (Marshuetz, 2005).

Tudi eksperimenti selektivnega motenja (angl. selective disruption), ki se osredotočajo na iskanje spremenljivk, ki ločeno motijo procesiranje informacij o vrstnem redu in identiteti dražljajev, so lahko dokaz za ločeno procesiranje obeh vrst informacij. Raziskave (Engelkamp in Dehn, 2000; Henson, Hartley, Burgess, Hitch in Flude, 2003; Mulligan, 1999) kažejo, da številne sočasne naloge (na primer tapkanje s prsti, nerelevanten govor in podobne) motijo procesiranje vrstnega reda, ne pa tudi identitete dražljajev. Poleg tega zahteva naloga vrstnega reda večjo stopnjo ponavljanja kot naloga pomnjenja identitete dražljajev (Henson idr., 2003). Hkratna potlačitev artikulacije, ki prepreči ponavljanje verbalnih dražljajev (Baddeley, 1986; Henson idr., 2003), ima namreč večji vpliv na procesiranje vrstnega reda kot na procesiranje identitete dražljajev.

Tudi skupkanje dražljajev v več podskupin ima različen vpliv na obe vrsti pomnjenja. Točnost odgovorov in reakcijski čas kot funkcija položaja dražljaja namreč kažeta, da ima skupkanje večji vpliv na pravilnost odgovorov pri nalogah vrstnega reda $\mathrm{V}$ primerjavi $\mathrm{Z}$ nalogami identitete (Henson idr., 2003). Skupkanje poveča pravilnost odgovorov in zmanjša reakcijski čas pri večini položajev pri nalogi vrstnega reda, medtem ko pri nalogi identitete nima vpliva (Henson idr., 2003).

Opisane študije nakazujejo, da so informacije o identiteti dražljajev ter njihovemu vrstnem redu v spominu predstavljene in procesirane ločeno (Marshuetz idr., 2000). V nadaljevanju si bomo podrobneje pogledali nekatere možne kognitivne mehanizme, s pomočjo katerih lahko pojasnimo kodiranje in priklic informacij o zaporedju. 


\section{Mehanizmi procesiranja vrstnega reda}

V preteklosti so številni raziskovalci naslovili vprašanje, kako se kodirajo informacije o vrstnem redu dražljajev oziroma dogodkov (na primer: Crowder, 1968; Shiffrin in Cook, 1978; Sternberg, 1967; Wickelgren, 1967; Young, 1962), kar je posledično pripeljalo do nastanka več hipotez in modelov. Glede na število in obseg modelov bi lahko sklepali, da je problem procesiranja vrstnega reda v kratkoročnem in delovnem spominu že rešen, vendar temu ni tako. Čeprav je napredek o védenju in veljavnosti teoretičnih perspektiv velik (Henson, 1998; 1999a; 2001), so mehanizmi, ki bi podrobneje razložili vse vidike procesiranja vrstnega reda, še vedno neznani in predmet številnih debat (Botvinick in Plaut, 2006).

Problemu vrstnega reda, to je kako ljudje shranjujemo in prikličemo nepoznano zaporedje dražljajev v ustreznem vrstnem redu, se posveča več modelov delovnega spomina (Henson, 1999a). V tem razdelku se bomo osredotočili na poglavitne mehanizme ter njihove vedenjske napovedi. Predpostavljeni mehanizmi niso medsebojno izključujoči, čeprav se empirični rezultati $\mathrm{v}$ določenih primerih ne skladajo s teoretičnimi napovedmi (Marshuetz, 2005). $\mathrm{V}$ ločevanju med različnimi modeli in mehanizmi imajo ključno vlogo trije pojavi, ki jih predstavljamo v nadaljevanju.

Najprej je potrebno omeniti Sternbergove rezultate naloge iskanja naslednika (angl. searching for next, Sternberg, 1967), kjer je opaziti podaljšanje reakcijskega časa v odvisnosti od položaja ciljnega dražljaja. Sternberg je v svoji paradigmi iskanja naslednika udeležencem prikazal zaporedje črk ali številk, ki jim je sledil ciljni dražljaj, udeleženci pa so morali sporočiti črko ali številko, ki se je v zaporedju pojavila za ciljnim dražljajem. Na primer, v spominskem nizu »7 193 « in pri ciljni številki »9« so udeleženci morali podati odgovor »3«. Vedenjski rezultati so pokazali, da reakcijski čas narašča s položajem ciljnega dražljaja. Drug pomemben pojav zasledimo v številnih nalogah zaporednega priklica, in sicer gre za napake, ki se pojavljajo pri priklicu (na primer: Henson, Norris, Page in Baddeley, 1996; Nairne, 1991; 1992). Med različnimi napakami, do katerih lahko pride pri priklicu, so verjetno najbolj pogoste napake transpozicije (udeleženec pravilno prikliče dražljaje, a v napačnem vrstnem redu) in intruzije (udeleženec napačno prikliče dražljaj, ki ni bil del prvotnega seta) (Henson, 1999a). Kadar niz dražljajev razdelimo v dve skupini (npr.: $\mathrm{F}$ G D - R T B, kjer se med obema podskupinama pojavi premolk), pa se pogosto pojavljajo interpozicije. Pri teh napakah se položaj znotraj skupine ohrani, medtem ko se spremeni položaj med skupinama (npr.: F T D - R G B) (Henson, 1999a). Tretji pomemben pojav pa je učinek razdalje (Moyer in Landauer, 1967), ki ga opazimo v primerih, ko mora udeleženec podati sodbo o vrstnem redu dveh dražljajev, njegov odgovor pa je hitrejši in bolj točen, če sta dražljaja med seboj bolj oddaljena. Na primer, če si mora udeleženec zapomniti serijo črk »B G F D K«, bo njegov odgovor o pravilnosti vrstnega reda hitrejši, če bosta kot ciljna dražljaja prikazana »G $\mathrm{K}$ « kot pa »G
$\mathrm{F} «$ ali »D K«, ki sta se v spominskem setu pojavila bolj skupaj v zaporedju. Analiza vzorcev napak kaže, da lahko učinek razdalje opazimo tudi pri nalogah zaporednega priklica, saj bomo sosednja dražljaja pogosteje priklicali v napačnem vrstnem redu, kar nakazuje, da imajo ti dražljaji več skupnih lastnosti (Nairne, 1991; 1992).

Nekateri avtorji menijo, da en sam mehanizem ne more razložiti vseh omenjenih pojavov (Marshuetz, 2005). Spomin za vrstni red informacij je tako verjetno opredeljen s kombinacijo različnih mehanizmov in ne z enim samim mehanizmom. V nadaljevanju si bomo pogledali nekatere mehanizme in za vsakega opredelili, kako dobro pojasnjuje izpostavljene pojave.

\section{Verižno kodiranje: Mehanizem meddražljajskih povezav}

Mehanizem verižnih povezav ali kodiranje glede na meddražljajsko povezanost, je teoretični mehanizem, ki oblikuje parne povezave med dražljaji v spominskem nizu (Henson, 1999b; Marshuetz, 2005; Marshuetz in Smith, 2006; Marshuetz idr., 2000; Sternberg, 1967). Glede na predpostavko verižnega kodiranja vrstni red shranjujemo preko oblikovanja povezav oziroma asociacij med zaporednimi dražljaji. Ob priklicu zaporedje obnovimo s sledenjem verižnim povezavam, v katerem vsak element predstavlja asociativni ključ za priklic svojega naslednika. Priklic prvega elementa vodi do avtomatskega priklica drugega elementa, ta do tretjega in tako naprej, dokler ni obnovljeno celotno zaporedje (Brown, Preece in Hulme, 2000; Henson, 1999a; 2001; Henson idr., 1996; Murdock, 1993). Mehanizem, ki uporablja meddražljajske povezave, bi kodiral spominski set »F D L J T« kot »F -> D, D -> L« in tako dalje.

Takšen asociativni mehanizem dovoljuje prehajanje čez dražljaje preko povezav z drugimi dražljaji in tako pravilno napove rezultate Sternbergove (1967) naloge iskanja naslednika. Strmo naraščanje reakcijskih časov $\mathrm{s}$ položajem $\mathrm{v}$ zaporedju lahko pojasnimo s tem, da posameznik venomer začne svoje iskanje na začetku spominskega seta in mora zato prehoditi več zaporednih povezav, če se ciljni dražljaj pojavi kasneje v zaporedju. Reakcijski časi za dražljaje na kasnejših položajih so zato daljši kot za dražljaje na začetku niza (Carpetner, Georgopoulos in Pellizzer, 1999; Sternberg, 1967). Vendar pa $\mathrm{s}$ tem modelom ne moremo razložiti rezultatov nalog presojanja pravilnosti zaporedja. Na podlagi predlaganega mehanizma bi namreč sklepali, da bodo reakcijski časi krajši za dražljaje, ki se v spominskem nizu nahajajo blizu, saj ko dostopimo do prve črke, naslednja neposredno sledi, rezultati pa kažejo ravno obratno - bolj kot sta si ciljna dražljaja v izvirnem nizu oddaljena, hitrejši so reakcijski časi sodb (Marshuetz, 2005; Marshuetz idr., 2000). Vendar pa avtorji pri tej razlagi ne upoštevajo, da se lahko z manjšo razdaljo med elementoma prvi element od obeh ciljnih dražljajev pojavi kasneje v nizu. To pomeni, da če posameznik vedno začne iskanje tarče na začetku, bo v povprečju kasneje prišel do prvega izmed prikazanih ciljnih elementov, zaradi česar bodo reakcijski časi pri bližnjih elementih v povprečju daljši. 
Poleg opisanega mehanizem povezav napoveduje, da kadar ne moremo priklicati enega od dražljajev, bomo imeli težave tudi pri priklicu kasnejših dražljajev (Marshuetz, 2005). Posledično, ko vrstni red dveh dražljajev iz nekega seznama zamenjamo, bi to moralo zmotiti tudi spomin za vse naslednje dražljaje v zaporedju. Baddeley (1968) je v eni svojih raziskav sestavil seznam črk, kjer so se črke na seznamih menjale med tistimi, ki so si bile fonološko podobne in s tem zamenljive (»P« in $» \mathrm{~V} \ll)$, ter tistimi, ki niso bile zamenljive, saj so fonološko zvenele zelo drugače (»R« in »Q«). Avtor poroča o visoki stopnji napak za fonološko zamenljive dražljaje, ne pa tudi za nezamenljive, ki so prvim sledili. Nezamenljivi dražljaji iz mešanih seznamov so bili namreč priklicani s prav takšno natančnostjo kot dražljaji iz seznama $\mathrm{s}$ samo nezamenljivimi črkami. Ta rezultat nakazuje, da se uspešen priklic dražljajev ne zanaša na uspešen priklic predhodnih dražljajev v zaporedju in da fonološko podobni in zamenljivi dražljaji ne vplivajo na priklic dražljajev, ki jim v zaporedju sledijo (Marshuetz, 2005; Schuck, Gaschler, Keisler in Frensch, 2012). Priklic določenega dražljaja tako ni nujno odvisen od priklica njegovega predhodnika, kar trdijo verižni modeli. Podobno kot Baddeley (1968) sta tudi Farrell in Lewandowsky (2003) testirala priklic udeležencev s pomočjo nizov, ki so jih sestavljali bodisi fonološko neskladni dražljaji bodisi zmes fonološko podobnih in različnih dražljajev. Glede na mehanizem meddražljajskih povezav bi sklepali, da bo priklic boljši v primeru različnih dražljajev, saj bo zmeda zaradi podobnosti minimalna. Vendar pa so rezultati pokazali ravno obratno, saj so bili fonološko različni dražljaji na mešanem seznamu priklicani bolje kot njihovi dvojniki na seznamu le raznolikih dražljajev. Možno je, da fonološka podobnost igra vlogo tako na ravni priklica in s tem povzroča zmedo med dražljaji, kot tudi na ravni meddražljajskih povezav, kar povzroča pravilni priklic naslednjega dražljaja v zaporedju zatem, ko se je pojavila zamenjava dveh dražljajev. Več napak ob priklicu se namreč lahko pojavi pri fonološko podobnih dražljajih, vendar pa je lažje osvežiti verigo povezav, kjer so si dražljaji fonološko podobni. Obratno v primeru seznama z nezamenljivimi dražljaji sicer težje izgubimo posamičen dražljaj, a ko se to zgodi, je prvotno verigo težje obnoviti (Marshuetz, 2005).

Tudi raziskave, kjer so na seznamu dražljajev določeno črko ponovili (na primer »D B R B S«), kažejo, da slabše prikličemo in se počasneje odzovemo na drugo ponovitev istega dražljaja (druga črka $» \mathrm{~B} \ll)$, vendar pa priklic ni slabši pri ostalih dveh dražljajih, ki sta ponovljeni črki sledila (»R« ali »S«). To zopet nasprotuje napovedim, ki izhajajo iz mehanizma meddražljajskih povezav (Henson idr., 1996; Kahana in Jacobs, 2000). Nizi s ponovljenimi dražljaji za mehanizem meddražljajskih povezav že v osnovi predstavljajo problem, saj ni jasno, kako naj bi potekalo procesiranje $\mathrm{v}$ primeru, ko je isti element povezan z dvema različnima odzivoma.

Mehanizem meddražljajskih povezav lahko torej ustrezno pojasni rezultate Sternbergove naloge iskanja naslednika, ne omogoča pa razlage vzorcev napak, ki se pojavljajo pri zaporednem priklicu (Henson idr., 1996). Prav tako ne razloži rezultatov pri fonološko podobnih seznamih dražljajev (Baddeley, 1968; Henson idr., 1996; Kahana in Jacobs, 2000) ter učinka razdalje (Marshuetz idr., 2000). Nekatere od težav lahko premostijo modeli, ki poleg parnih povezav med zaporednimi elementi predpostavljajo tudi obstoj oddaljenih asociacij med dražljaji. $\mathrm{V}$ tem primeru priklic posamičnega elementa temelji na skupku predhodnih odzivov, tovrstna »nedavna zgodovina« predhodnih dražljajev pa omogoča, da lahko najdemo ustrezen odziv tudi na ponovljene dražljaje (Henson, 2001).

\section{Mehanizem neposrednega kodiranja}

Mehanizem neposrednega kodiranja predpostavlja, da je položaj vsakega dražljaja $v$ spominskem setu označen neposredno, na primer »F-prvi, P-drugi, Dtretji ...« (Anderson in Matessa, 1997; Brown, Morin in Lewandowsky, 2006; Farrell, 2008; Marshuetz, 2005; Schuck idr., 2012). Dražljaji so tako povezani s svojim lastnim položajem glede na začetek seznama. Takšno neposredno ali absolutno kodiranje položaja ni občutljivo na hitrost prikaza dražljajev, saj je koda za tretji zaporedni dražljaj v nizu, kjer so dražljaji hitro prikazani, enaka kodi tretjega dražljaja v zaporedju, kjer dražljaje predvajamo počasi. Absolutno kodiranje položaja prav tako ni občutljivo na dolžino zaporedja, saj je koda za tretji dražljaj v zaporedju treh dražljajev enaka kodi tretjega dražljaja v zaporedju petih dražljajev.

Neposredno kodiranje predvideva pomanjkanje naučenih asociacij in transferja med različnimi nalogami (Marshuetz, 2005). Če dražljaji nikoli niso bili neposredno povezani eden $\mathrm{z}$ drugim, potem ni razloga, da bi ta naučenost predstavljala prednost pri povezanih dražljajih. Nadalje lahko neposredno kodiranje razloži učinek vaje in fonološke zamenjave (Baddeley, 1968; Marshuetz, 2005). Ker priklic ni odvisen od povezav dražljajev med seboj, tudi ni razloga, da bi pričakovali manjšo natančnost za dražljaje, ki sledijo ponovljenim ali zamenljivim dražljajem, saj je vsak dražljaj shranjen v ločenem »predalu « (Henson, 2001; Marshuetz, 2005). Prav tako lahko ta model razloži pravilni priklic dražljajev, ki sledijo napačnim odzivom, saj se lahko priklic nadaljuje v naslednjem predalu v spominu, čeprav je bila vsebina trenutnega predala priklicana napačno (Henson, 2001).

Vendar pa tudi enostavno neposredno kodiranje ne more razložiti vseh vedenjskih fenomenov. Eden izmed teh je učinek razdalje. Če neposredne kode smatramo kot ordinalne kvantitete, potem pričakujemo ravne krivulje reakcijskih časov in pravilnosti odgovorov $\mathrm{v}$ funkciji meddražljajske razdalje, saj lahko neposredno dostopamo do položajev posameznega dražljaja in vsako od položajskih kod primerjamo med seboj, česar pa empirični podatki ne kažejo (Marshuetz idr., 2000; Moyer in Landauer, 1967; Nairne, 1991; 1992). Vendar pa obstaja nekoliko bolj izdelan mehanizem neposrednih povezav, ki predvideva tudi učinek razdalje. Eden izmed njih je model, v katerem neposredne kode obravnavamo kot velikosti (angl. magnitudes), ki jih primerjamo med seboj. Večja kot je razlika v velikosti, lažje razlikujemo položaj dražljajev in hitrejši ter bolj natančni so odgovori udeleženca (Marshuetz, 2005). Če imamo spominski set 
»B L D F T « in ustrezne kode (1, 2, 3, itd.), potem mora biti odziv udeleženca hitrejši, kadar sta kot ciljni dražljaj prikazana »B T« v primerjavi $\mathrm{z} » \mathrm{~B} \mathrm{D} \ll$ ali $» \mathrm{~B} \mathrm{~L} \ll$, saj je razlika med velikostjo ordinalnih kod $\mathrm{v}$ prvem primeru večja (na primer: Neath in Crowder, 1990).

Poleg težav pri razlagi učinka razdalje, ima enostavni mehanizem neposrednega kodiranja težave tudi pri razlagi nekaterih drugih pojavov. S težavo namreč razloži najbolj pogosto napako, ki jo zasledimo pri tovrstnih nalogah, to je zamenjava dveh sosednjih dražljajev. Ena izmed možnosti je, da položajske kode niso samostojne, ampak se med seboj prekrivajo (Henson, 2001). Nekateri (Johnson, 1991) so mnenja, da bi enostavni mehanizem neposrednega kodiranja moral posamezniku omogočiti tudi natančno sodbo o časovni poziciji določenega dražljaja v spominskem nizu, a raziskave kažejo, da to ni mogoče (Marshuetz, 2005). Poleg tega ima mehanizem neposrednega kodiranja težave tudi pri razlagi rezultatov naloge iskanja naslednika. Sternberg (1967) namreč poroča o učinku položaja v nizu, kar pomeni, da dražljaje s konca seznama prikličemo počasneje kot tiste iz začetka seznama. Enostavni mehanizem neposrednega kodiranja pa ne predvideva tovrstnih rezultatov, saj bi moral posameznik do kode dostopati neposredno, poiskati naslednjo položajsko kodo in priklicati $\mathrm{z}$ njo povezan dražljaj. Opisani enostavni mehanizmi tako niso več $\mathrm{v}$ ospredju, v večini so jih nadomestili mehanizmi velikostnega kodiranja, mehanizmi razlikovanja in mehanizmi hierarhičnega kodiranja.

\section{Mehanizem hierarhičnega kodiranja}

Mehanizem hierarhičnega kodiranja predstavlja nekoliko bolj izpopolnjeno različico mehanizma neposrednega kodiranja. Sloni na predpostavki, da so dražljaji avtomatsko združeni v podskupine po tri ali več dražljajev. Ti dražljaji so kodirani najprej na podlagi njihove skupine, nato pa še na podlagi položaja znotraj skupine (Burgess in Hitch, 1992; 1999; Marshuetz, 2005).

Mehanizem hierarhičnega kodiranja podpirata dve vrsti empiričnih spoznanj. Prvo je spoznanje, da je zaporedni priklic boljši, če dražljaje znotraj seznama razdelimo v podskupine (na primer: Miller, 1956). Drugo pa je, da se napake vrstnega reda znotraj grupiranih zaporedij razlikujejo od tistih pri negrupiranih zaporedjih (Henson, 1999a). V negrupiranih zaporedjih se pogosto zgodi, da zamenjamo položaja dveh sosednjih dražljajev. $\mathrm{V}$ grupiranih sekvencah pa pogosteje zamenjujemo dražljaje, ki zavzemajo enake pozicije znotraj podskupine. Eden najbolj znanih modelov hierarhičnega kodiranja je Leejev in Estesov model (Lee in Estes, 1981), v katerem je informacija o položaju dražljajev znotraj skupine gnezdena pod informacijo o položaju skupine v sekvenci. Tak mehanizem dobro pojasni učinek razdalje, vendar potrebuje nekaj manjših prilagoditev. Če predvidevamo, da je informacija o skupini lažje in hitreje dostopna kot informacija o položaju znotraj skupine, potem bodo dražljaji, ki so bolj narazen, z večjo verjetnostjo pripadali različnim skupinam kot pa sosednji dražljaji. Verjetnost, da dražljaja pripadata različnima skupinama, pa je manjša z manjšanjem razdalje med dvema dražljajema. Zato za odločitev o sosednjih dražljajih potrebujemo dostop do informacije na stopnji dražljajev znotraj skupine, medtem ko odločitev o zaporedju dražljajev zrazdaljo treh dražljajev skoraj vedno lahko naredimo zgolj z dostopanjem do informacije o skupini (Marshuetz, 2005). Vendar pa tak mehanizem ne predvideva transferja meddražljajskih povezav med različnimi nalogami, saj meddražljajskih povezav v tem primeru ni. Edina povezava, ki se pojavi, je med dražljajem in njegovim položajem in skupino. Prav tako ta mehanizem le delno pojasni rezultate, ki jih dobimo z nalogo iskanja naslednika, če sklepamo, da je skupinska informacija dostopna zaporedno. To pomeni, da do dražljajev, ki pripadajo drugi skupini, dostopamo počasneje kot pa do tistih, ki se nahajajo v prvi skupini.

\section{Mehanizem velikostnega kodiranja}

Mehanizem velikostnega kodiranja (angl. magnitude coding) predvideva, da je informacija o vrstnem redu položajska, a kodirana $\mathrm{v}$ analogni in ne diskretni obliki, brez eksplicitne informacije o skupini (Marshuetz, 2005; Neath in Crowder, 1990). Ta mehanizem postavi dražljaje na imaginarni analogni kontinuum, pri čemer so bližnje kode položaja bolj podobne ena drugi kot pa kode, ki se nahajajo dlje stran ena od druge. Informacija o zaporedju je $\mathrm{v}$ tem primeru torej predstavljena $\mathrm{s}$ kontinuiranim indeksom velikosti. Vedenjski rezultati bi tako morali biti vzporedni psihofizičnim funkcijam, kot so diskriminacija velikosti (Marshuetz idr., 2000). To pomeni, da če so dražljaji kodirani glede na kontinuum časovne oddaljenosti, bolj kot so dražljaji ločeni v času, lažja bi morala biti odločitev o njihovem pravilnem oziroma napačnem zaporedju.

Primer takega modela je na nihanjih osnovan asociativni priklic (angl. oscillator-based associative recall, OSCAR, Brown idr., 2000). Mehanizem kodiranja položaja dražljaja v OSCAR modelu je podoben analogni uri. Tovrstne ure imajo mnogo kazalcev, vsak od njih niha $\mathrm{z}$ različno frekvenco (eden obkroži uro vsakih 12 ur, drugi vsako uro, tretji vsako minuto). Sekundni kazalec je tako dober za ločevanje majhnih časovnih razlik, vendar se ponovi vsako minuto, medtem ko sta minutni in urni kazalec potrebna za ločevanje med urama 8:05:30 in 12:07:30. Te nihajne kode so povezane $\mathrm{z}$ vsakim izmed dražljajev. Gre torej za časovno kodiranje položaja, kjer je vsak dražljaj povezan s časom svojega pojava, kar se kaže s stanjem časovnih oscilatorjev različnih frekvenc (Henson, 2001). Zamenjave ali izgube položajskih informacij se lahko pojavijo, ko so si nihajne kode med seboj zelo podobne, ali če primerjamo z analogijo z uro, ko sta položajski kodi enaki 4:03 in 4:04. Ponovitev je dosežena tako, da postavimo oscilatorje nazaj $\mathrm{v}$ prvotni položaj, položaj dražljajev pa lahko dosežemo v naprejšnjem vrstnem redu (Marshuetz, 2005).

Takšen nihajni mehanizem uporabljajo tudi v mnogo drugih modelih. V modelu začetka (angl. primacy model, Page in Norris, 1998) lahko vrstni red procesiramo s kodiranjem moči dražljaja, ki pa upada s položajem v 
zaporedju. Preko kodiranja časovnega položaja je vsak dražljaj povezan s časom svojega prikaza oziroma pojava, morda relativno glede na začetek, lahko pa tudi glede na konec zaporedja, kot je to v modelu konca (angl. recency model, Neath, 1993).

Tudi Grossberg (1978) je podobno sklepal, da je vrstni red reprezentiran $\mathrm{z}$ močjo dražljajev v spominu, kjer je prvi dražljaj najmočnejši, zadnji pa najšibkejši. Vrstni red dražljajev lahko obnovimo $\mathrm{z}$ iterativnim procesom, tako da izberemo najmočnejši dražljaj in ga začasno potlačimo, da lahko prikličemo naslednji najmočnejši dražljaj, in tako naprej. Če je v ta proces dodan naključni šum, lahko ta selekcijski proces povzroči vzorec napak v vrstnem redu. Podoben je tudi Hensonov model začetka in konca (angl. start-end model, SEM, Henson, 1998), ki prav tako vključuje dva analogna mehanizma, ki kodirata vrstni red. Eden izmed njih se začne na začetku zaporedja, njegova moč pa proti koncu pojenja, končni označevalec oziroma mehanizem pa je najmočnejši na koncu sekvence in najšibkejši na začetku. Vrstni red je kodiran glede na položaj znotraj seznama $\mathrm{v}$ odnosu do začetka in konca in ni neposredno povezan s sosednjimi dražljaji ter zaporednimi kodami (Marshuetz, 2005). Tovrstno kodiranje relativnega položaja sklepa, da so dražljaji kodirani tako glede na začetek, kot tudi glede na konec zaporedja (Henson, 1999b). Relativna moč začetnega in končnega označevalca prispeva dvodimenzionalno kodo za vsak položaj znotraj zaporedja. Takšno relativno kodiranje položaja je občutljivo na dolžino zaporedja, saj je koda tretjega dražljaja v zaporedju treh dražljajev različna od kode tretjega dražljaja $\mathrm{v}$ zaporedju petih dražljajev - v prvem primeru je namreč dražljaj zabeležen kot konec zaporedja (najšibkejši prvi označevalec in najmočnejši drugi označevalec), medtem ko je v drugem primeru zabeležen kot sredina zaporedja (prvi in drugi označevalec srednje moči).

Mehanizmi velikostnega kodiranja so na nek način podobni mehanizmu neposrednega kodiranja, le da so kode multidimenzionalne (Marshuetz, 2005). Ti modeli tako obdržijo mnogo prednosti modelov neposrednega kodiranja, hkrati pa se znebijo nekaterih njihovih pomanjkljivosti. Tako ne predvidevajo več, da bo udeleženec brez težav priklical eksplicitni zaporedni položaj, kot predvideva mehanizem neposrednega kodiranja (Anderson in Matessa, 1997; Brown idr., 2006; Farrell, 2008; Schuck idr., 2012). Poleg tega vsi velikostni modeli lahko razložijo kodiranje vrstnega reda ne da bi se posluževali meddražljajskih povezav.

Mehanizem velikostnega kodiranja lahko pojasni nekatere vidike vedenjskih podatkov. V nalogi zaporednega priklica bomo sosednje dražljaje zamenjali z večjo verjetnostjo kot dražljaje, ki so v zaporedju bolj oddaljeni (Johnson, 1991; Nairne, 1991), kar je skladno z velikostnim mehanizmom, saj imajo sosednji dražljaji bolj podobne reprezentacije. Poleg tega lahko model razloži učinek razdalje, saj imajo dražljaji, ki so bolj oddaljeni v zaporedju, manj podobne reprezentacije in se bomo na vprašanje o njihovem zaporedju odzvali hitreje in točneje v primerjavi z odzivom na vprašanje o zaporedju sosednjih dražljajev, katerih koda je bolj podobna. Ta pojav kaže, da so predstave velikosti in kvantitete dražljajev shranjene kot velikosti, ki jih med seboj lažje razlikujemo, bolj ko so si različne (Marshuetz idr., 2000). Vendar pa tudi ta mehanizem ne zmore pojasniti vseh pojavov, ki jih opazimo pri priklicu vrstnega reda $\mathrm{v}$ Sternbergovi nalogi iskanja naslednika. Če dražljaji niso neposredno povezani eden z drugim, se mora odločitev, kateri dražljaj sledi določenemu dražljaju na seznamu, z ocenjevanjem velikostnih kod pojaviti neposredno, to je brez prehoda preko meddražljajskih povezav. Na podlagi tega bi torej sklepali, da bodo pri nalogi iskanja naslednjika reakcijski časi, ko udeleženec poišče ustrezni dražljaj, ki je sledil tarčnemu, neodvisni od položaja, kar pa je v nasprotju z vedenjskimi rezultati (Sternberg, 1967).

\section{Povzetek teoretičnih mehanizmov beleženja zaporedja}

$\mathrm{V}$ tem razdelku smo opisali nekatere glavne lastnosti ter vedenjske rezultate, ki jih predvidevajo različni kognitivni mehanizmi beleženja vrstnega reda. Osredotočili smo se na štiri pomembnejše mehanizme, in sicer na verižne mehanizme meddražljajskih povezav, na mehanizme neposrednega kodiranja, hierarhične mehanizme ter mehanizme velikostnega kodiranja. Vsak izmed njih lahko pojasni nekatere vidike procesiranja vrstnega reda, vendar pa pri vsakem hkrati najdemo tudi pomanjkljivosti, ki jih je potrebno ustrezno nasloviti.

Enostavni asociativni mehanizem oziroma mehanizem meddražljajskihpovezav dobropojasniučinekzaporednega položaja, ki se pogosto kaže v vedenjskih nalogah kot je iskanje naslednika. Ti mehanizmi tudi dobro pojasnijo dejstvo, da težko prikličemo natančen zaporedni položaj nekega dražljaja, saj bi morali na določen položaj sklepati s štetjem povezav, ki jih moramo do dražljaja prehoditi. Vendar pa ima ta mehanizem težave pri razlagi učinka razdalje ter določenih vzorcev napak.

Mehanizemneposrednega kodiranja lahko prilagodimo tako, da uspešno pojasni učinek razdalje, vendar pa hkrati neustrezno napoveduje sposobnost natančnega priklica položaja, na katerem se je posamičen dražljaj pojavil. Poleg tega ima tudi težave pri razlagi vedenjskih podatkov Sternbergove naloge iskanja naslednika. Zaradi opisanih težav so raziskovalci mehanizem neposrednega kodiranja v večini zavrnili, zamisel o kodi zasnovani na položaju pa je bila vključena $v$ številne modele procesiranja vrstnega reda.

Mehanizem hierarhičnega kodiranja ima enake prednosti kot mehanizem neposrednega kodiranja in torej dobro razloži učinek razdalje ter pomanjkanje transferja meddražljajskih povezav, vendar pa ima tudi nekaj težav pri razlagi specifičnih pojavov. Težko razloži Sternbergove rezultate pri nalogi iskanja naslednika, težave pa ima tudi pri razlagi posameznikove nesposobnosti podajanja točnega položaja dražljaja.

Modeli velikostnega kodiranja lahko dobro pojasnijo učinek razdalje ter nenatančno naravo informacije o vrstnem redu, imajo pa težave pri razlagi vedenjskih rezultatov Sternbergove naloge iskanja naslednika. Tega je sicer možno pojasniti z dodatno predpostavko o mehanizmu naprejšnjega pregledovanja (angl. forward- 
scanning mechanism), za katerega pa se zdi, da ni skladen z učinkom razdalje (Marshuetz, 2005).

Procesiranje vrstnega reda dražljajev je kompleksen proces, zato ni presenetljivo, dazenim samimmehanizmom ni možno pojasniti vseh podatkov in vedenjskih rezultatov nalog vrstnega reda. Predlagani mehanizmi se razlikujejo $\mathrm{v}$ napovedih vedenjskih rezultatov, predvidevamo pa lahko, da temeljijo tudi na različnih živčnih procesih (Marshuetz in Smith, 2006). Zaradi svoje kompleksne narave je povsem verjetno, da je vrstni red procesiran in beležen s pomočjo več kot enega samega mehanizma. Od vseh predstavljenih modelov so trenutno modeli, ki slonijo na mehanizmu velikostnega kodiranja, najuspešnejši in najbolj fleksibilni pri pojasnjevanju znanih lastnosti beleženja zaporedja (Marshuetz, 2005).

\section{Zaključki}

Na podlagi številnih raziskav (na primer: Bjork in Healy, 1974; Engelkamp in Dehn, 2000; Henderson in Matthews, 1970; Henson idr., 2003; McElree in Dosher, 1993; Mulligan, 1999) je danes uveljavljeno mnenje, da obstajata vsaj dve vrsti informacij v spominu, prva je informacija o dražljajih samih, druga pa informacija o njihovem vrstnem redu. Na vedenjski ravni smo videli, da so informacije o identiteti in vrstnem redu dražljajev vzdrževane in priklicane ločeno (Engelkamp in Dehn, 2000; Henson idr., 2003; McElree in Dosher, 1993; Marshuetz, 2005; Mulligan, 1999), ta ločenost pa obstaja na kognitivni ravni tako pri prepoznavi (McElree in Dosher, 1993; Sternberg, 1967), kot tudi pri priklicu (Brown idr., 2000; Burgess in Hitch, 1992; Henson, 1998; Lee in Estes, 1981; Page in Norris, 1998).

Še vedno ostaja odprto vprašanje, ali obstaja tudi več različnih vrst spomina za informacije o vrstnem redu. Rezultati študij podpirajo predpostavko, da je vrstni red beležen in predstavljen na več stopnjah. S tem se skladajo tudi številni modeli in mehanizmi beleženja vrstnega reda $\mathrm{v}$ delovnem spominu. Vsak izmed njih je uspešen pri razlagi določenih vidikov vedenja, nobenemu pa ne uspe pojasniti vseh. Možno je, da je časovna komponenta predstavljena kot niz lastnosti ali pa da obstajajo različni živčni oscilatorji, ki delujejo na različnih frekvencah (Marshuetz, 2005). Vprašanje je tudi, kako so komponente naučenih zaporedij organizirane $\mathrm{v}$ pravem vrstnem redu, da se izognejo nejasnostim med zaporedji, ki vsebujejo podobne komponente (Agam, Huang in Sekuler, 2010; Keele, Ivry, Mayr, Hazeltine in Heuer, 2003). Ta problem je še posebej relevanten $v$ zgodnjih fazah učenja, pri prvih srečanjih $\mathrm{z}$ informacijo o zaporedju, preden se vzpostavijo višjeredne povezave med dražljaji (Agam idr., 2010).

Kljub temu, da je problem vrstnega reda živ že več desetletij (na primer: Bjork in Healy, 1974; Conrad, 1965; Henderson in Matthews, 1970; Sternberg, 1966; 1967), ostajajo številna vprašanja glede načina procesiranja informacij o zaporedju še vedno odprta. Z novejšimi slikovnimi metodami smo v zadnjem času deležni novih spoznanj in $\mathrm{z}$ njimi povezanih teoretičnih napredkov. Zanimivo bo videti, kakšna vprašanja in odgovore bo podalo nadaljnje raziskovalno delo.

\section{Literatura}

Acheson, D. J. in MacDonald, M. C. (2009). Verbal working memory and language production: Common approaches to the serial ordering of verbal information. Psychological Bulletin, 135(1), 50-68.

Agam, Y., Huang, J. in Sekuler, R. (2010). Neural correlates of sequence encoding in visuomotor learning. Journal of Neurophysiology, 103(3), 1418-1424.

Anderson, J. R. in Matessa, M. (1997). A production system theory of serial memory. Psychological Review, 104(4), 728-748.

Awh, E., Jonides, J., Smith, E. E., Schumacher, E. H., Koeppe, R. A. in Katz, S. (1996). Dissociation of storage and rehearsal in verbal working memory: Evidence from positron emission tomography. Psychological Science, 7(1), 25-31.

Baddeley, A. (1968). How does acoustic similarity influence short-term memory? Quarterly Journal of Experimental Psychology, 20(3), 249-264.

Baddeley, A. (1986). Working memory. Oxford, Velika Britanija: Clarendon Press.

Baddeley, A. (2002). Is working memory still working? European Psychologist, 7(2), 85-97.

Baddeley, A. (2003). Working memory: Looking back and looking forward. Nature Reviews Neuroscience, 4(10), 829-839.

Baddeley, A. (2007). Working memory, thought, and action. Oxford, Velika Britanija: Oxford University Press.

Bjork, E. J. in Healy, A. F. (1974). Short-term order and item retention. Journal of Verbal Learning and Verbal Behavior, 13(1), 80-97.

Botvinick, M. M. in Plaut, D. C. (2006). Short-term memory for serial order: A recurrent neural network model. Psychological Review, 113(2), 201-233.

Brown, G. D. A., Morin, C. in Lewandowsky, S. (2006). Evidence for time-based models of free recall. Psychonomic Bulletin and Review, 13(4), 717-723.

Brown, G. D. A., Preece, T. in Hulme, C. (2000). Oscillatorbased memory for serial order. Psychological Review, 107(1), 127-181.

Burgess, N. in Hitch, G. J. (1992). Toward a network model of the articulatory loop. Journal of Memory and Language, 31(4), 429-460.

Burgess, N. in Hitch, G. J. (1999). Memory for serial order: A network model of the phonological loop and its timing. Psychological Review, 106(3), 551-581.

Cabeza, R., Mangels, J., Nyberg, L., Habib, R., Houle, S., McIntosh, A. R. in Tulving, E. (1997). Brain regions differentially involved in remembering what and when: a PET study. Neuron, 19(4), 863-870.

Cabeza, R., Nichole, N. D., Houle, S., Mangels, J. A. in Nyberg, L. (2000). Age-related differences in neural activity during item and temporal-order memory retrieval: A positron emission tomography study. Journal of Cognitive Neuroscience, 12(1), 197-206.

Cantor, J. in Engle, R. W. (1993). Working-memory capacity as long-term memory activation: An individual-differences approach. Journal of 
Experimental Psychology: Learning, Memory, and Cognition, 19(5), 1101-1114.

Carpenter, A. F., Georgopoulos, A. P. in Pellizzer, G. (1999). Motor cortical encoding of serial order in a context-recall task. Science, 283(5408), 1752-1757.

Carretti, B., Borella, E., Cornoldi, C. in De Beni, R. (2009). Role of working memory in explaining the performance of individuals with specific reading comprehension difficulties: A meta-analysis. Learning and Individual Differences, 19(2), 246-251.

Conrad, R. (1965). Order error in immediate recall of sequences. Journal of Verbal Learning and Verbal Behavior, 4(3), 161-169.

Cowan, N. (1993). Activation, attention, and short-term memory. Memory \& Cognition, 21(2), 162-167.

Crowder, R. G. (1968). Evidence for the chaining hypothesis of serial verbal learning. Journal of Experimental Psychology, 76(4), 497-500.

Daneman, M. in Merikle, P. M. (1996). Working memory and language comprehension: A meta-analysis. Psychonomic Bulletin and Review, 3(4), 422-433.

Dell, G. S., Burger, L. K. in Svec, W. R. (1997). Language production and serial order: A functional analysis and a model. Psychological Review, 104(1), 123-147.

D’Esposito, M., Detre, J. A., Alsop, D. C., Shin, R. K., Atlas, S. in Grossman, M. (1995). The neural basis of the central executive system of working memory. Nature, 378(6554), 279-281.

D’Esposito, M., Postle, B. R., Ballard, D. in Lease, J. (1999). Maintenance versus manipulation of information held in working memory: An event-related fMRI study. Brain and Cognition, 41(1), 66-86.

Engelkamp, J. in Dehn, D. M. (2000). Item and order information in subject-performed tasks and experimenter-performed tasks. Journal of Experimental Psychology: Learning, Memory, and Cognition, 26(3), 671-682.

Farrell, S. (2008). Multiple roles for time in shortterm memory: Evidence from serial recall of order and timing. Journal of Experimental Psychology: Learning, Memory, and Cognition, 34(1), 128-145.

Farrell, S. in Lewandowsky, S. (2003). Dissimilar items benefit from phonological similarity in serial recall. Journal of Experimental Psychology: Learning, Memory, and Cognition, 29(5), 838-849.

Gathercole, S. E. in Baddeley, A. D. (1990). Phonological memory deficits in language-disordered children: Is there a causal connection? Journal of Memory and Language, 29(3), 336-360.

Goldman-Rakic, P. S. (1995). Architecture of the prefrontal cortex and the central executive. Annals of the New York Academy of Sciences, 769(1), 71-83.

Goldman-Rakic, P. S. (1996). The prefrontal landscape: Implications of functional architecture for understanding human mentation and the central executive. Philosophical Transactions of the Royal Society B: Biological Sciences, 351(1346), 1445-1453.

Grossberg, S. (1978). Behavioral contrast in short-term memory: Serial binary memory models or parallel continuous memory models? Journal of Mathematical Psychology, 17(3), 199-219.
Gupta,P.inMacWhinney,B.(1997). Vocabularyacquisition and verbal short-term memory: Computational and neural bases. Brain and Language, 59(2), 267-333.

Henderson, L. in Matthews, M. L. (1970). Perception and memory loss of item and order information in short-term memory. Attention, Perception, \& Psychophysics, 9(2), 231-233.

Henson, R. N. A. (1998). Short-term memory for serial order: The start-end model. Cognitive Psychology, 36(2), 73-137.

Henson, R. N. A. (1999a). Coding position in short-term memory. International Journal of Psychology, 34(5), 403-409.

Henson, R. N. A. (1999b). Positional information in short-term memory: Relative or absolute? Memory \& Cognition, 27(5), 915-927.

Henson, R. N. A. (2001). Serial order in short-term memory. The Psychologist, 14(2), 70-73.

Henson, R. N. A., Burgess, N. in Frith, C. D. (2000). Recoding, storage, rehearsal and grouping in verbal short-term memory: An fMRI study. Neuropsychologia, 38(4), 426-440.

Henson, R. N. A., Hartley, T., Burgess, N., Hitch, G. in Flude, B. (2003). Selective interference with verbal short-term memory for serial order information: A new paradigm and tests of a timing signal hypothesis. Quarterly Journal of Experimental Psychology section A: Human Experimental Psychology, 56(8), 1307-1334.

Henson, R. N. A., Norris, D. G., Page, M. P. A. in Baddeley, A. D. (1996). Unchained memory: Error patterns rule out chaining models of immediate serial recall. Quarterly Journal of Experimental Psychology section A: Human Experimental Psychology, 49(1), 80-115.

Johnson, G. J. (1991). A distinctiveness model of serial learning. Psychological Review, 98(2), 204-217.

Johnson, M. K., Raye, C. L., Mitchell, K. J., Greene, E. J. in Anderson, A. W. (2003). fMRI evidence for organization of prefrontal cortex by both type of process and type of information. Cerebral Cortex, 13(3), 265-273.

Jonides, J., Lacey, S. C. in Nee, D. E. (2005). Processes of working memory in brain and mind. Current Directions Psychological Science, 14(1), 2-5.

Jonides, J., Smith, E. E., Marshuetz, C., Koeppe, R. A. in Reuter-Lorenz, P. A. (1998). Inhibition in verbal working memory revealed by brain activation. Proceedings of the National Academy of Sciences of the United States of America, 95(14), 8410-8413.

Just, M. A. in Carpenter, P. A. (1992). A capacity theory of comprehension: Individual differences in working memory. Psychological Review, 99(1), 122-149.

Kahana, M. J. in Jacobs, J. (2000). Interresponse times in serial recall: Effects of intraserial repetition. Journal of Experimental Psychology: Learning, Memory, and Cognition, 26(5), 1188-1197.

Kane, M. J. in Engle, R. W. (2002). The role of prefrontal cortex in working-memory capacity, executive attention and general fluid intelligence: An individual differences perspective. Psychonomic Bulletin and Review, 9(4), 637-671. 
Keele, S. W., Ivry, R., Mayr, U., Hazeltine, E. in Heuer, H. (2003). The cognitive and neural architecture of sequence representation. Psychological Review, 110(2), 316-339.

Kyllonen, P. C. in Christal, R. E. (1990). Reasoning ability is (little more than) working-memory capacity?!. Intelligence, 14(4), 389-433.

Leclercq, A.-L. in Majerus, S. (2010). Serial-order shortterm memory predicts vocabulary development: Evidence from a longitudinal study. Developmental Psychology, 46(2), 417-427.

Lee, C. L. in Estes, W. K. (1981). Item and order information in short-term memory: Evidence for multilevel perturbation processes. Journal of Experimental Psychology: Human Learning and Memory, 7(3), 149-169.

Marshuetz, C. (2005). Order information in working memory: An integrative review of evidence from brain and behavior. Psychological Bulletin, 131(3), 323-339.

Marshuetz, C. in Smith, E. E. (2006). Working memory for order information: Multiple cognitive and neural mechanisms. Neuroscience, 139(1), 195-200.

Marshuetz, C., Smith, E. E., Jonides, J., DeGutis, J. in Chenevert, T. L. (2000). Order information in working memory: fMRI evidence for parietal and prefrontal mechanisms. Journal of Cognitive Neuroscience, 12(2), 130-144.

McElree, B. in Dosher, B. A. (1993). Serial retrieval processes in the recovery of order information. Journal of Experimental Psychology: General, 122(3), 291-315.

Miller, G. A. (1956). The magical number seven, plus or minus two: Some limits on our capacity for processing information. Psychological Review, 63(2), 81-97.

Moyer, R. S. in Landauer, T. K. (1967). Time required for judgments of numerical inequality. Nature, 215(5109), 1519-1520.

Mulligan, N. W. (1999). The effects of perceptual interference at encoding on organization and order: Investigating the roles of item-specific and relational information. Journal of Experimental Psychology: Learning, Memory, and Cognition, 25(1), 54-69.

Murdock, B. B. (1993). TODAM2: A model for the storage and retrieval of item, associative, and serial order information. Psychological Review, 100(2), 183-203.

Nairne, J. S. (1991). Positional uncertainty in long-term memory. Memory \& Cognition, 19(4), 332-340.

Nairne, J. S. (1992). The loss of positional certainty in long-term memory. Psychological Science, 3(3), 199-202.

Neath, I. (1993). Distinctiveness and serial position effects in recognition. Memory \& Cognition, 21(5), 689-698.

Neath, I. in Crowder, R. G. (1990). Schedules of presentation and temporal distinctiveness in human memory. Journal of Experimental Psychology: Learning, Memory, and Cognition, 16(2), 316-327.
Owen, A. M., McMillan, K. M., Laird, A. R. in Bullmore, E. (2005). N-back working memory paradigm: A meta-analysis of normative functional neuroimaging studies. Human Brain Mapping, 25(1), 46-59.

Page, M. P. A. in Norris, D. (1998). The primacy model: A new model of immediate serial recall. Psychological Review, 105(4), 761-781.

Salthouse, T. A. (1993). Influence of working memory on adult age differences in matrix reasoning. British Journal of Psychology, 84(2), 171-199.

Schuck, N. W., Gaschler, R., Keisler, A. in Frensch, P. A. (2012). Position-item associations play a role in the acquisition of order knowledge in an implicit serial reaction time task. Journal of Experimental Psychology: Learning, Memory, and Cognition, 38(2), 440-456.

Shiffrin, R. M. in Cook, J. R. (1978). Short-term forgetting of item and order information. Journal of Verbal Learning and Verbal Behavior, 17(2), 189-218.

Smith, E. E. in Jonides, J. (1999). Storage and executive processes in the frontal lobes. Science, 283(5408), 1657-1661.

Smith, E. E., Jonides, J. in Koeppe, R. A. (1996). Dissociating verbal and spatial working memory using PET. Cerebral Cortex, 6(1), 11-20.

Sternberg, S. (1966). High-Speed Scanning in Human Memory. Psychonomic Science, 8(2), 55-56.

Sternberg, S. (1967). Retrieval of contextual information from human memory. Science, 153(3736), 652-654.

Wickelgren, W. A. (1967). Rehearsal grouping and hierarchical organization of serial position cues in short-term memory. Quarterly Journal of Experimental Psychology, 19(2), 97-102.

Young, R. K. (1962). Tests of three hypotheses about the effective stimulus in serial learning. Journal of Experimental Psychology, 63(3), 307-313.

Zheng, X., Swanson, H. L. in Marcoulides, G. A. (2011). Working memory components as predictors of children's mathematical word problem solving. Journal of Experimental Child Psychology, 110(4), 481-498. 